\title{
PENGARUH WAKTU PENGADUKAN TERHADAP WAKTU GELASI BAHAN CETAK ALGINAT
}

\author{
Audia Tria Putri ${ }^{1}$, Rizanda Machmud ${ }^{2}$ dan Murniwati ${ }^{3}$ \\ ${ }^{1}$ Fakultas Kedokteran Gigi Universitas Andalas, Padang, Sumatera Barat, Indonesia \\ ${ }^{2}$ Departemen Public Health, Fakultas Kedokteran Gigi, Universitas Andalas, Padang, Sumatera Barat, Indonesia
}

\begin{abstract}
Alginate is one of many dental materials that used for the impressing materials. Mixing time is one of factors that affected the setting time. The aim of this study was to determine the effect of mixing time at 30 seconds, 35 seconds, 40 seconds, 45 seconds, 50 seconds, 55 seconds and 60 seconds on setting time of alginate. This study used experimental method. The samples that used were 42 samples and divided into 7 groups of mixing time, that were 30 seconds (control), 35 seconds, 40 seconds, 45 seconds, 50 seconds, 55 seconds, and 60 seconds. Setting time was tested with acrylic test rod based on ADA specification no.18. The alginate powder was mixed with water (10 gr: $23 \mathrm{ml}$ ratio), then put in the mould. Acrylic test rod was placed in contact with the surface of alginate dough. The setting time was measured from the starting of the mix to the time when alginate does not adhere to the end of the rod. Result of this study showed that the average of setting time of alginate which mixed for 30 seconds (control), 35 seconds, 40 seconds, 45 seconds, 50 seconds, 55 seconds, and 60 seconds was $120.17 \pm 3.312$ seconds, $119.00 \pm 1.265$ seconds, $118.17 \pm 1.472$ seconds, $114.83 \pm 3.896$ seconds, $112.00 \pm$ 1.673 seconds, $109.17 \pm 0.983$ seconds, and $105.33 \pm 4.082$ seconds respectively.

One Way Anova test shows significant difference among all experimental group with $p=0.000$. The change of setting time alginate show significant difference with control group when it mixed for 45 seconds, 50 seconds, 55 seconds, and 60 seconds.
\end{abstract}

Keywords: alginate, mixing time, setting time

Affiliasi penulis: Fakultas Kedokteran Gigi, Universitas Andalas, Padang, Sumatera Barat, Indonesia

Korespondensi: Audia Tria Putri

e-mail: audia.triaputri@yahoo.com

\section{PENDAHULUAN}

Penggunaan bahan cetak dalam kedokteran gigi dilakukan untuk mendapatkan hasil cetakan negatif dari jaringan rongga mulut. Alginat merupakan salah satu bahan cetak yang sangat lazim digunakan. Alginat merupakan bahan cetak hidrokoloid ireversibel elastis yang digunakan untuk membuat cetakan gigi tiruan sebagian lepasan dengan kawat, cetakan pre-eliminasi primer untuk gigi tiruan penuh, cetakan orthodontik serta cetakan model studi. ${ }^{1}$
Alginat memiliki sejumlah keuntungan yaitu mudah digunakan, tidak memerlukan perlengkapan khusus saat melakukan pengadukan, ekonomis dan bersifat tidak toksik. ${ }^{2}$ Keuntungan lain yang dimiliki oleh alginat yaitu memiliki aroma yang menyenangkan dan pengecoran hasil cetakan lebih mudah dilakukan dibanding dengan bahan cetak lainnya.,

Manipulasi alginat dapat dilakukan secara manual dengan menggunakan tangan dan juga dapat dilakukan secara mekanis dengan menggunakan alginator. ${ }^{5}$ Teknik pengadukan angka delapan dengan cepat dan menggunakan spatula adalah teknik terbaik untuk mengaduk alginat secara manual. ${ }^{6}$ 
Waktu pengadukan amatlah penting dalam manipulasi bahan cetak alginat, karena kekuatan gel dapat berkurang sampai $50 \%$ bila pengadukan tidak sempurna. Waktu pengadukan untuk pengadukan secara manual dengan tangan adalah 45 detik sampai 1 menit bergantung pada merek dan jenis alginat, sedangkan untuk pengadukan secara mekanis dibutuhkan waktu 15 detik. Hasilnya harus berupa campuran seperti krim yang halus serta tidak menetes dari spatula ketika diangkat dari mangkuk. ${ }^{5,6}$

Waktu kerja merupakan waktu yang dihitung mulai dari proses pengadukan alginat hingga bahan cetak dapat ditempatkan di dalam rongga mulut tanpa mengalami distorsi. ${ }^{7}$ Dilihat dari definisi yang dipaparkan, maka waktu pengadukan merupakan bagian dari waktu kerja alginat. $^{3}$

Alginat merupakan bahan cetak yang mengeras dengan reaksi pembentukan gel kalsium alginat. Sekali gelasi terjadi, bahan cetak tidak boleh diganggu karena fibril yang sedang terbentuk akan patah dan cetakan menjadi lebih lemah. ${ }^{8}$ Waktu gelasi dihitung mulai dari pengadukan hingga terjadinya proses gelasi yang sempurna pada alginat. ${ }^{3}$

Dalam keadaan klinis, ada kecenderungan untuk mengubah waktu gelasi dari alginat, yaitu dengan mengganti rasio air terhadap bubuk atau waktu pengadukan. Cara lain yang dapat dilakukan adalah dengan mengubah temperatur air. ${ }^{8}$ Pengendalian waktu gelasi perlu dilakukan agar tidak terjadi prematur gelasi pada bahan cetak. ${ }^{6}$ Alasan lain perlunya melakukan pengendalian waktu gelasi adalah karena seringnya ditemukan keluhan berupa rasa mual pada pasien saat dilakukan pencetakan. ${ }^{9}$

Beberapa penelitian telah dilakukan terkait dengan pengendalian waktu gelasi bahan cetak alginat. Penelitian mengenai perubahan waktu gelasi bahan cetak alginat pada temperatur air yang berbeda-beda dilakukan oleh Dekky J. pada tahun 2013. Hasil penelitian ini menunjukkan bahwa semakin rendah suhu air yang digunakan maka semakin lama waktu gelasi alginat. ${ }^{10}$

Dyah dkk. pada tahun 2009 melaporkan bahwa terdapat hubungan antara temperatur ruangan dengan waktu gelasi dari bahan cetak alginat. Hasil dari penelitian ini menunjukkan terdapat kontribusi yang besar dari temperatur ruangan terhadap waktu gelasi pada alginat $(0,74 \%$ untuk normal set alginat dan $0,88 \%$ untuk fast set alginat). ${ }^{11}$

Penetilian Melisa dkk. pada tahun 2009 menyebutkan bahwa terdapat hubungan antara waktu gelasi alginat dengan penurunan rasio air dan bubuk. Penelitian ini menggunakan 4 grup sampel yaitu 
penurunan $0 \%$ (kontrol). 5\%, 10\%, $15 \%$, dari volume air. Hasil penelitian ini menunjukkan penurunan rasio air dan bubuk bahan cetak alginat dapat mempercepat waktu gelasi. ${ }^{12}$

Sejauh yang peneliti ketahui belum ada penelitian tentang hubungan waktu pengadukan terhadap waktu gelasi alginat. Oleh karena itu peneliti tertarik untuk mengetahui pengaruh waktu pengadukan terhadap waktu gelasi bahan cetak alginat.

\section{METODE PENELITIAN}

Penelitian ini merupakan penelitian eksperimental laboratoris dengan desain post test only control group design. Penelitian dilakukan di ruang skills lab Fakultas Kedokteran Gigi Universitas Andalas. Penelitian ini dilakukan pada bulan Februari 2016. Sampel yang digunakan dalam penelitian ini adalah 1 bungkus bahan cetak alginat.

Jumlah pengulangan sampel dalam penelitian ini ditentukan berdasarkan rumus untuk penelitian eksperimental. ${ }^{13}$

$$
(\mathrm{t}-1)(\mathrm{n}-1) \geq 15
$$

$$
\mathrm{n} \geq 3.5
$$

Berdasarkan rumus diatas, diperoleh jumlah pengulangan sampel minimal sama dengan atau lebih dari 3.5 pada masing masing kelompok. Peneliti mengambil pengulangan sampel sebanyak 6 buah untuk tiap kelompok.
Dalam penelitian ini, jumlah sampel seluruhnya adalah 42 yang dibagi dalam 1 kelompok kontrol dan 6 kelompok perlakuan.

1. Kelompok $1: 6$ buah sampel diaduk dengan waktu pengadukan 30 detik. (kontrol)

2. Kelompok $2: 6$ buah sampel diaduk dengan waktu pengadukan 35 detik.

3. Kelompok 3 : 6 buah sampel diaduk dengan waktu pengadukan 40 detik.

4. Kelompok 4 : 6 buah sampel diaduk dengan waktu pengadukan 45 detik.

5. Kelompok $5: 6$ buah sampel diaduk dengan waktu pengadukan 50 detik.

6. Kelompok 6 : 6 buah sampel diaduk dengan waktu pengadukan 55 detik.

7. Kelompok $7: 6$ buah sampel diaduk dengan waktu pengadukan 60 detik.

\section{HASIL PENELITIAN}

Sebelum dilakukan uji One Way Anova, terlebih dahulu dilakukan uji normalitas data dengan menggunakan uji Shapiro Wilk. Berdasarkan hasil uji normalitas menggunakan uji Shapiro Wilk menunjukkan bahwa data terdistribusi normal karena nilai $\mathrm{p}>0.05$, yaitu $\mathrm{p}=0.147$.

Selanjutnya dilakukan uji One Way Anova. Pada uji One Way Anova didapatkan nilai $\mathrm{p}$ sebesar 0.000 . Hal ini memperlihatkan bahwa adanya perbedaan signifikan $(\mathrm{p}<0.05)$ antara sampel yang 
diaduk selama 30 detik, 35 detik, 40 detik, 45 detik, 50 detik, 55 detik, dan 60 detik.

\section{PEMBAHASAN}

Penelitian ini dilakukan untuk mengetahui pengaruh waktu pengadukan terhadap waktu gelasi bahan cetak alginat. Sampel yang digunakan dalam penelitian ini berjumlah 42 sampel dengan pengulangan 6 buah sampel untuk tiap kelompok. Sampel diaduk dengan waktu pengadukan selama 30 detik, 35 detik, 40 detik, 45 detik, 50 detik, 55 detik, dan 60 detik. Penentuan waktu pengadukan berdasarkan waktu pengadukan yang tertera pada kemasan alginat yang digunakan yaitu selama 30 detik. Waktu pengadukan yang dianjurkan dalam Anusavice (2004) yaitu antara 45 detik sampai 60 detik. Dengan mengacu pada hal tersebut, waktu pengadukan dilakukan antara rentang 30 detik sampai 60 detik dengan interval 5 detik antar masing masing kelompok.

Proses pengadukan yang dilakukan pada penelitian ini dilakukan secara manual dengan menggunakan tangan dan spatula. Jumlah pengadukan yaitu 2 kali per detik yang dihitung dengan menggunakan metronom mengacu pada penelitian Melisa pada tahun 2009 .

Pengukuran waktu gelasi bahan cetak alginat menggunakan batang akrilik sebagai alat ukur dengan cara menyentuhkan ujung alat ukur pada permukaan adonan alginat. Waktu gelasi dihitung mulai dari awal pencampuran alginat hingga tidak ada lagi bahan cetak alginat yang menempel pada ujung alat ukur. Hal ini mengacu pada penelitian yang dilakukan oleh Indrani (2013) dan Irnawati (2009).

Dalam melakukan penelitian ini, peneliti dibantu oleh beberapa orang mahasiswa kedokteran gigi. Pengadukan bahan cetak alginat dan pengukuran waktu gelasi dilakukan oleh 3 orang operator termasuk peneliti. Operator tersebut sebelumnya telah dilatih dan diberikan pengarahan sehingga memiliki presepsi yang sama dengan peneliti.

Reaksi waktu gelasi merupakan sebuah reaksi kimia. Boundless (2015) menyatakan bahwa salah satu faktor yang mempengaruhi laju reaksi kimia adalah luas permukaan molekul yang berkontak satu sama lain. Semakin luas permukaan molekul yang berkontak maka semakin cepat laju reaksi terjadi. Semakin lama suatu bahan diaduk, semakin banyak tumbukan yang terjadi maka semakin luas permukaan yang berkontak dan semakin cepat laju reaksi.

Anusavice (2004) menyatakan bahwa waktu gelasi alginat dipengaruhi oleh banyak faktor, seperti rasio W/P, waktu pencampuran, dan suhu air. Craig 
(2012) menyebutkan bahwa semakin banyak jumlah pengadukan dalam satu menit, maka semakin cepat waktu gelasi dan sebaliknya.

\begin{tabular}{|c|c|c|c|}
\hline Kelompok & $\mathrm{n}$ & $\begin{array}{l}\text { Mean } \pm \\
\text { SD }\end{array}$ & $\mathrm{p}$ \\
\hline $\begin{array}{c}1(30 \\
\text { detik) }\end{array}$ & 6 & $\begin{array}{l}120.17 \pm \\
3.312\end{array}$ & 0.000 \\
\hline $2(35$ detik $)$ & 6 & $\begin{array}{l}119.00 \\
1.265\end{array}$ & \\
\hline 3 (40 detik) & 6 & $\begin{array}{l}118.17 \\
1.472\end{array}$ & \\
\hline $4(45$ detik $)$ & 6 & $\begin{array}{l}114.83 \quad \pm \\
3.896\end{array}$ & \\
\hline 5 (50 detik) & 6 & $\begin{array}{l}112.00 \\
1.673\end{array}$ & \\
\hline 6 (55 detik) & 6 & $\begin{array}{l}109.17 \quad \pm \\
0.983\end{array}$ & \\
\hline 7 (60 detik) & 6 & $\begin{array}{l}105.33 \\
4.082\end{array}$ & \\
\hline
\end{tabular}

Pada perbandingan rata-rata waktu gelasi yang terjadi akibat pengaruh waktu pengadukan, didapatkan bahwa semakin lama waktu pengadukan yang dilakukan maka semakin cepat waktu gelasi yang terjadi. Hal ini terlihat dari rata-rata waktu gelasi pada kelompok 1 sebesar 120.17 detik, rata-rata waktu gelasi kelompok 2 adalah 119.00 detik, rata-rata waktu gelasi kelompok 3 adalah 118.17 detik, rata-rata waktu gelasi kelompok 4 adalah 114.83 detik, rata-rata waktu gelasi kelompok 5 adalah 112.00 detik, rata-rata waktu gelasi kelompok 6 adalah 109.17 detik, dan ratarata waktu gelasi kelompok 7 adalah 105.33 detik.

Dari hasil penelitian yang dilakukan, terlihat pengaruh waktu pengadukan terhadap waktu gelasi alginat. Hasil uji One Way Anova menunjukkan adanya perbedaan yang signifikan antar kelompok dengan nilai $\mathrm{p}<0.05$ yaitu $\mathrm{p}=0.000$.

Waktu gelasi yang cepat disebabkan karena waktu pengadukan yang lebih lama dalam pemanipulasian alginat. Waktu pengadukan yang lama menyebabkan bertambahnya jumlah pengadukan yang dilakukan. Meningkatnya jumlah pengadukan berarti meningkat pula jumlah tumbukan yang terjadi sehingga laju reaksi makin cepat. Pada waktu pengadukan yang lebih sebentar, laju reaksi akan berlangsung lambat sehingga waktu gelasi akan menjadi lebih lama.

Selain dilakukan uji One Way Anova untuk melihat pengaruh secara keseluruhan pada semua kelompok, juga dilakukan uji beda lanjutan dengan menggunakan uji Postx Hoc LSD untuk melihat perbedaan antar kelompok. Hasilnya menunjukkan bahwa kelompok yang memiliki perbedaan waktu gelasi yang bermakna yaitu antara kelompok kontrol(30 detik) dengan kelompok 4(45 
detik), kelompok kontrol dengan kelompok 5 (50 detik),

kelompok kontrol dengan kelompok 6(55 detik), dan kelompok kontrol dengan kelompok 7(60 detik).

Hasil penelitian ini mendukung penelitian lain yang dilakukan Pawlak pada tahun 2010 yang melihat pengaruh waktu pengadukan terhadap waktu gelasi gipsum plaster. Hasil penelitiannya menyebutkan bahwa waktu dan jumlah pengadukan sangat mempengaruhi waktu gelasi gipsum plaster. Penelitian ini sesuai dengan teori Koudi (2007) yang menyatakan bahwa waktu gelasi gipsum dapat diperpendek dengan cara memperpanjang waktu pengadukan dan meningkatkan jumlah pengadukan.

Berdasarkan hasil penelitian yang dilakukan dapat disimpulkan bahwa waktu pengadukan dapat mempengaruhi waktu gelasi bahan cetak alginat yang bermakna secara statistik saat kelompok kontrol dibandingkan dengan kelompok 45 detik, 50 detik, 55 detik, dan 60 detik. Keterbatasan pada penelitian ini yaitu pengadukan alginat yang dilakuan secara manual sehingga tidak bisa dipastikan bahwa kekuatan saat pengadukan pada tiap sampel sama besar.

\section{KESIMPULAN}

Dari hasil penelitian mengenai pengaruh waktu pengadukan terhadap waktu gelasi bahan cetak alginat, dapat disimpulkan bahwa bahan cetak yang diaduk dengan waktu pengadukan 45 detik, 50 detik, 55 detik, dan 60 detik memiliki perbedaan waktu gelasi yang bermakna bila dibandingkan dengan bahan cetak yang diaduk dengan waktu pengadukan 30 detik (kontrol).

\section{KEPUSTAKAAN}

1. O'Brien WJ. 2002. Dental materials and their selection 3rd ed. Chicago: Quintessence, hal 173-176

2. Gaurav Solank.,Sumeet Sharma. 2014. A review on alginat impression material. Journal of Pharmaceutical Biology vol 4(3), hal $155-157$

3. Lyra, Edu. 2000. Alginat Impression. Available from URL : lyra.ifas.ufl.edu/ LyraServlet?command=display\&port $=205$ $0 \&$ style $=$ Dentistry $\% 20$ Navigator $\% 20$ Fram $\mathrm{e} \% 20$ Style \& content $=3518 \&$ class $=3519 \& \mathrm{~m}$ odule $=3518 \&$ parent $0=$ Dentistry

4. Marcia (Gladwin) Stewart, R.D.H., Ed.D. 2001. Clinical aspects of dental material theory,practice and cases. $4^{\text {th }}$ ed. Morgantown: West Virginia, hal 117-118

5. Nandini VV, Venkatesh KV, Nair KC. 2008. Alginate impressons : a practical prespective. Journal conservative dentistry vol 11, hal 37-41

6. Annusavice KJ. 2003. Phillips' science o $f$ dental materials 11th ed. St. Louis: Elsevier, hal 242

7. Craig RG., Powers JM. 2002. Restorative dental materials 11th ed. St Louis: CV Mosby Co., hal 280;283

8. 8.Annusavice KJ. 2004. Phillips' science of dental materials 10th ed. Jakarta: EGC, hal 103-110

9. Ellis G. 2014. Alginate Impression and Diagnostic Study Model Techniques. ADA CERP. [internet]. Available from URL:http://www.dentalcare.com

10. Decky J.Indriani.,Niti Matram. 2013. Changes in setting time of alginat impression material with different 
temperatur.Dental Journal Universitas Airlangga vol 46, p 5-8. [internet]. Available from URL : journal.unair.ac.id/changes-in-

setting-time-of-alginate-impressionmaterial-with-different-water-temperaturearticle-6117-media-2-category-3.html

11. Dyah I.,Siti S. 2009. Functional relationship of room temperatur and setting time of alginat impression material.Dental Journal Universitas Airlangga vol.42,p 137-140. [internet]. Available for URL

http://journal.unair.ac.id/functionalrelationship-of-room-temperature-and setting-time-of-alginate-impressionmaterial-article-3004-media-2-category 3.html

12. Melisa TP.,dkk. 2009. Setting time due to alginat impression materials $w / p$ ratio reduction.Material Dental Journal Universitas Airlangga vol.1 hal 37-40

13. Hidayat AA. 2011. Metode penelitian keperawatan dan teknik analisis data. Jakarta : Salemba Medika 